\title{
Educação infantil diante da pandemia causada pela Covid-19: no cenário o programa Rio Preto Educ Ação
}

\author{
Childhood education towards the pandemic caused by Covid-19: \\ on the scenario the Rio Preto Educ Ação program
}

\section{Educación infantil antes de la pandemia por Covid-19: en el escenario programa Rio Preto Educ Ação}

\author{
Aline Sommerhalder \\ http://orcid.org/0000-0002-6024-0853 \\ Raiza Fernandes Bessa de Oliveira² \\ https://orcid.org/0000-0002-2422-482I \\ Giseli Alcassas Masson ${ }^{3}$ \\ https://orcid.org/0000-0003-3020-789X
}

Resumo: Este estudo tem como foco a educação infantil em contexto de pandemia causada pela Covid-19, uma vez que muito se tem visto e se discutido sobre esta etapa, sendo as atividades pedagógicas a distância fator de

\footnotetext{
' Pós-doutora em Educação pela Università di Roma Tre (Roma/ltália). Docente Associada do Departamento de Teorias e Práticas Pedagógicas e do Programa de Pós-Graduação em Educação da UFSCar - Universidade Federal de São Carlos, campus de São Carlos/SP. Coordenadora do Centro de Pesquisa da Criança e de Formação de Educadores da Infância - Cfei/CNpq. E-mail: sommeralinel@gmail.com

${ }^{2}$ Doutoranda em Educação pela UFSCar - Universidade Federal de São Carlos. Membro do Centro de Pesquisa da Criança e de Formação de Educadores da Infância - Cfei/CNpq. Professora e Formadora de professores na Secretaria Municipal de Educação de São José do Rio Preto - SP. E-mail: raizafbessa@gmail.com

${ }^{3}$ Mestre em Educação pela UFSCar - Universidade Federal de São Carlos. Professora e Formadora de professores na Secretaria Municipal de Educação de São José do Rio Preto - SP. E-mail: g.alcassas@gmail.com
}

Olhar de professor, Ponta Grossa, v. 24, p. I-8, e-I5596.026, 2021.

Disponível em <https://revistas2.uepg.br/index.php/olhardeprofessor> 
preocupação por parte de pesquisadores e educadores da primeira infância. Se caracteriza como um estudo de natureza qualitativa, como estudo de caso documental e objetiva apresentar e discutir brevemente alguns aspectos da implementação de um Programa Educacional Municipal, criado em contexto pandêmico, evidenciando possibilidades de trabalho, mas também alguns limites e desafios. Os dados indicaram estratégias e ferramentas que possibilitaram a continuidade de vínculo entre escolas, professores(as), crianças e famílias, bem como a continuidade de trabalho dos docentes. Infere-se, também, a necessidade de avaliação constante de ações e propostas vinculadas a esse Programa, objetivando que sejam intencionais, efetivas e não excludentes, garantindo os direitos educacionais de bebês e crianças, mesmo em um cenário tão complexo, urgente e inédito.

Palavras-chave: Educação infantil. Pandemia Covid-19. Atividades pedagógicas a distância.

Abstract: This study focuses on early childhood education in the context of a pandemic caused by Covid-19, since much has been seen and discussed about this stage, with distance teaching activities being a factor of concern by researchers and educators from early childhood. It is characterized as a qualitative and as a documentary case study and aims to briefly present and discuss some aspects of the implementation of a municipal Educational Program, created in a pandemic context, showing possibilities of work, but also some limits and challenges. The data indicate strategies and tools that enabled the continuity of links between schools, teachers, children and families, as well as the continuity of the teachers' work. It is also inferred the need for constant evaluation of actions and proposals linked to this Program, aiming at being intentional, effective and not excluding, guaranteeing the educational rights of babies and children, even in such a complex, urgent and unprecedented scenario.

Keywords: Early childhood education. Covid-19 Pandemic. Distance pedagogical activities.

Resumen: Este estudio se centra en la educación infantil en el contexto de una pandemia ocasionada por Covid19, ya que mucho se ha visto y discutido sobre esta etapa, siendo la actividad de enseñanza a distancia un factor de preocupación por parte de investigadores y educadores de la primera infancia. Se caracteriza por ser un estudio cualitativo, como un caso de estudio documental y tiene como objetivo presentar y discutir brevemente algunos aspectos de la implementación de un Programa Educativo municipal, creado en un contexto de pandemia, mostrando posibilidades de trabajo, pero también algunos límites y desafíos. Los datos indicaron estrategias y herramientas que permitieron la continuidad de los vínculos entre escuelas, docentes, niños y familias, así como la continuidad del trabajo de los docentes. También se infiere la necesidad de una evaluación constante de las acciones y propuestas vinculadas a este Programa, con objetivo de ser intencionales, efectivas y no excluyentes, garantizando los derechos educativos de los bebés y niños, incluso en un escenario tan complejo, urgente y sin precedentes.

Palabras-clave: Educación infantil, Pandemia de Covid-19. Actividades pedagógicas a distancia.

\section{Introdução}

O presente artigo aborda o tema da educação infantil brasileira em contexto de pandemia causada pela Covid-19, considerando os impactos no cotidiano da sociedade e nas instituições escolares. Diante disso, muito se tem visto e discutido sobre a educação infantil, sendo as atividades pedagógicas a distância fator de grande preocupação por parte de pesquisadores/as e educadores/as da primeira infância, considerando que nessa etapa a convivência no coletivo escolar e as práticas de cuidar e de educar, tendo as interações e a brincadeira como eixos centrais, orientam as ações cotidianas.

A preocupação se acentua em relação à garantia dos direitos educacionais e sociais de bebês e de crianças pequenas, por meio de uma pedagogia específica e do reconhecimento das infâncias como tempo singular de desenvolvimento e de aprendizagem, mesmo em um contexto de pandemia, inédito para todos. 
O texto trata da problemática das atividades pedagógicas a distância, destinadas às crianças de 0 a 5 anos na educação infantil e objetiva apresentar e discutir brevemente alguns aspectos da implementação de um Programa Educacional municipal - a saber, Programa Rio Preto Educ Ação, criado em 2020 em contexto pandêmico -, evidenciando algumas possibilidades de trabalho, limites e desafios.

Em 2020, o Brasil e outros países foram impactados com a pandemia causada pela Covid-19, que desencadeou a necessidade urgente de isolamento ou distanciamento social, visando o combate à disseminação do vírus e ao adoecimento populacional. Isso resultou, dentre outras condutas, na suspensão do atendimento presencial nas escolas, públicas e privadas, em todos os níveis de ensino.

Em abril do mesmo ano, foi aprovado pelo Conselho Nacional de Educação um parecer que regulamenta as práticas escolares durante o período de pandemia, validando a utilização de atividades pedagógicas a distância, inclusive na educação infantil, de modo a "minimizar a necessidade de reposição presencial de dias letivos, a fim de permitir que seja mantido um fluxo de atividades escolares aos estudantes" (ESTRELA; LIMA, 2020, online).

A aprovação deste parecer foi contra a Lei de Diretrizes e Bases da Educação Nacional n.9394/96 (BRASIL, 1996), que não prevê atividades pedagógicas a distância para bebês e crianças pequenas, mesmo em situações emergenciais. Tal indicação culminou em críticas de instituições de educação infantil, pesquisadores/as e professores/as sobre encaminhamentos de atividades pedagógicas a distância para essa faixa etária, reiterando a necessidade de reconhecer a educação infantil como uma etapa educativa que se realiza em experiências sustentadas pelo afeto e vínculo, convivência em coletivo de pares, de natureza interacional e práticas educativas intencionais e planejadas, que tenham como eixos estruturantes as interações e a brincadeira nas práticas cotidianas de educar e de cuidar (BRASIL, 2009).

A inadequação de atividades pedagógicas a distância na educação infantil inclui considerar que esses encaminhamentos podem se apresentar abdicados de intencionalidade ou de articulação entre si, bem como ficarem apartadas da realidade social das escolas públicas e do cotidiano das próprias crianças, o que pode acentuar desigualdades educacionais e sociais.

Do mesmo modo, é equivocado supor que as famílias possuem condições e recursos necessários para darem continuidade ao processo educacional que antes se realizava nas escolas. A problemática se acentua quando se considera os contextos diversos das comunidades atendidas pela educação infantil pública, os mais pobres economicamente e assim, tecnologicamente, o que torna tais propostas potencialmente excludentes.

Torna-se preocupante, também, o modo como professores/as de educação infantil têm participado dessas ações. É fato que, em muitos casos, se veem obrigados a produzir vídeos e materiais de forma solitária e disponibilizá-los em redes sociais e/ou plataformas educacionais, ou ainda 
estabelecer contato frequente, por meio de aplicativos como WhatsApp ou Facebook, por exemplo, uma vez que os municípios nem sempre possuem plataformas digitais, para que tenham contabilizada sua carga horária de trabalho (CORREIA; CÁSSIO, 2020; SOUSA, 2020).

\section{Caminho metodológico}

Este estudo tem abordagem qualitativa (BOGDAN; BIKLEN, 1994), caracterizando-se como um estudo de caso documental. Realizou-se, assim, descrição de algumas ações e propostas para a educação infantil, bem como a discussão dos documentos: I. Roteiros de estudo de Teletrabalho docente; 2. Adaptação para Educação Infantil - Orientações às famílias dos estudantes das redes estadual e municipal de São Paulo; 3. Brincadeiras e Interações: um convite às famílias e crianças para brincarem juntas; 4. Relatórios de avaliação de ações, todos de composição do Programa Rio Preto Educ Ação, do município de São José do Rio Preto - SP.

Tomou-se como foco, neste texto, a educação infantil, considerando a especificidade dessa etapa educativa e a complexa rede necessária a ser implementada para aproximação com as famílias, bebês e crianças, bem como possibilidade de continuidade do trabalho de professores/as e gestores/as. Os dados foram tratados na perspectiva qualitativa, à luz de referencial teórico.

\section{Resultados e discussão}

A educação infantil, nessa rede municipal de ensino, conta com 98 escolas municipais, além de 14 parceiras/conveniadas, aproximadamente 1.200 docentes e 20 mil crianças entre 0 e 5 anos de idade (SÃO JOSÉ DO RIO PRETO, 20I9). É um enorme coletivo de bebês e crianças pequenas que ficaram temporariamente sem atendimento presencial.

Com o Decreto Municipal $n^{\circ} 18.583$ de 9 de abril de 2020 - regulamentado pela Resolução $n^{\circ}$ 04/2020 de 14 de abril - a SME deu início ao Programa Rio Preto Educ Ação. O exame deste Programa, em termos de intencionalidade, evidenciou que o objetivo central foi apoiar o ensino e o estudo de matriculados na rede municipal e também $\circ$ trabalho de professores/as, durante $\circ$ período de suspensão do atendimento presencial nas escolas. No que se refere à educação infantil, o Programa teve por intenção:

§ $1^{\circ}$ - A Educação Infantil (creche e pré-escola), onde o Cuidar e Educar são indissociáveis para a promoção do desenvolvimento infantil, as atividades de apoio aos estudos dos alunos pautar-se-ão pelas brincadeiras e interações, com o acompanhamento das famílias (SÃO JOSÉ DO RIO PRETO, 2020b, p. 2).

Olhar de professor, Ponta Grossa, v. 24, p. I-8, e-15586.026, 202 I.

Disponível em <https://revistas2.uepg.br/index.php/olhardeprofessor> 
Os eixos brincadeira e interações foram colocados como centralidade buscando sustentar-se nos documentos políticos e curriculares vigentes na educação infantil brasileira. Desde abril de 2020, o Programa desenvolveu um conjunto de ações e propostas, como: reestruturação do site Educação Digital, criação de Facebook e Youtube oficiais, produção de roteiros de estudo para os professores/as, disponibilização às crianças e famílias de materiais de apoio, criação de e-mails institucionais para gestores/as e professores/as, criação de Google Classroom para gestores/as, produção e veiculação de conteúdos educativos na TV Câmara, oferta de cursos a distância, elaboração pelas equipes escolares de propostas de estudos aos matriculados na rede e aproximações das famílias dos estudantes, acompanhamento e apoio, pela equipe de Capacitação, aos gestores no desenvolvimento de ações.

O exame dessas ações e propostas mostra a materialização de atividades de apoio, por parte dessa SME e de organização de ferramentas de comunicação e de interação para o âmbito educacional, tanto para famílias e crianças, quanto para os profissionais da educação. Entretanto, entende-se as limitações das propostas, uma vez que muitas famílias da rede municipal não possuem acesso a recursos digitais e internet de qualidade, por exemplo, dificuldade que também é encontrada em relação aos próprios profissionais da educação.

$\mathrm{Na}$ educação infantil, para a continuidade do trabalho, caracterizado como regime de teletrabalho dos/as professores/as, os Roteiros de estudo de Teletrabalho docente foram elaborados pela SME em abril e em maio. A análise do material de abril indicou a organização em torno das temáticas: educação integral e competências gerais, presentes na Base Nacional Comum Curricular (BRASIL, 2018) e no Currículo Paulista (SÃO PAULO, 2019). A análise do roteiro de maio evidenciou uma organização em blocos, indicando as seguintes atividades de estudo: indicações culturais, aprofundamento da rotina de trabalho; concepções do currículo, de criança, de infância e da função social da educação infantil; estudos sobre a pandemia e seus impactos na educação e na sociedade, e estudos sobre a cultura digital. Evidencia-se que o estudo destes temas por parte dos docentes se mostra relevante para a reflexão e continuidade de seu trabalho junto às crianças e famílias, buscando a construção de conhecimento que permita a elaboração de propostas que caminhem na direção da concepção de criança como ser ativo, potente e de direitos.

O material Adaptação para Educação Infantil - Orientações às famílias dos estudantes das redes estadual e municipal de São Paulo foi criado no mês de abril e disponibilizado às escolas e comunidade, para aproximação das crianças e famílias da educação infantil. $O$ exame deste documento mostra a composição de repertório de experiências lúdicas, indicando que resultou de uma adaptação de material da Secretaria Estadual de Educação e da União Nacional dos Dirigentes Municipais de Educação - UNDIME (SÃO PAULO, 2020). 
Já o documento Brincadeiras e Interações: um convite às famílias e crianças para brincarem juntas (SÃO JOSÉ DO RIO PRETO, 2020a), produzido pela equipe de formadoras da educação infantil, também evidenciou um registro de atividades para incentivo à realização de brincadeiras pelas crianças junto as suas famílias. A análise desse material indicou que o mesmo intenciona ampliar as possibilidades e experiências infantis por meio de sugestões, incluindo imagens e materiais variados, de simples composição e de fácil acesso, desencadeando ações para continuidade de vínculo com famílias, bebês e crianças, mesmo reconhecendo as limitações desse gênero textual. Os dois materiais foram disponibilizados em formato impresso e digital.

De modo geral, esses materiais revelaram a intencionalidade de propor atividades adequadas às crianças dessa faixa etária, ampliando as possibilidades e experiências que elas poderiam vivenciar em contexto familiar, buscando minimizar os impactos da suspensão do atendimento presencial nas escolas. Ao reconhecer que a educação infantil se efetiva por meio das experiências sustentadas pelo afeto e vínculo, interações e brincadeira, reconhece-se, também, as limitações dessas ações.

A elaboração desse material teve desdobramento em mais uma ação, que foi a produção e veiculação de conteúdos educativos em parceria com a TV Câmara do município - Programa Educ Ação na TV. Na educação infantil, esse projeto contou com a participação efetiva de 42 professores(as) e 5 gestores(as), que se inscreveram por meio de formulário e foram acompanhados pela equipe de formadoras. Ao todo, o exame dessa ação mostrou uma organização com exibição de 7 episódios, que tiveram como conteúdos: leitura, contação de histórias, brincadeiras, brincadeiras cantadas, propostas com arte, dentre outros.

Os Relatórios de avaliação de ações (SÃO JOSÉ DO RIO PRETO, 2020d) evidenciam que os participantes avaliaram muito positivamente a ação de exibição dos episódios, indicando como uma possibilidade importante diante do contexto. Os profissionais indicaram ainda que obtiveram retorno das crianças e famílias, o que fortaleceu vínculos e ampliou as possibilidades de atuação, além de ter se caracterizado como fonte de conhecimento e formação para os envolvidos.

Reconhecendo a inadequação do uso de telas (TV, tablets, celulares) por bebês e crianças bem pequenas, a maior parte das propostas para essa faixa etária foi elaborada em uma linguagem direcionada ao adulto (familiar), por exemplo, para a construção de brinquedos, produção de tintas naturais, massinhas e melecas, condução de brincadeiras e explorações, explicitando a importância das diversas experiências oferecidas.

Outra ação, que mediante a análise neste estudo, se mostrou bastante significativa foi o oferecimento de curso de formação, com carga horária de 30 horas, versando sobre os recursos do pacote Google for Education (Meet, Drive, Apresentações, Documentos, Classroom). De agosto a setembro de 2020, foram abertas duas turmas, com uma vaga por unidade escolar, das quais 
participaram 62 professores(as) da educação infantil. Dados dos Relatórios de avaliação de ações indicam que, para os cursistas, esta ação mostrou-se muito potente, como uma possibilidade para formação, uma vez que muitos não sabiam fazer uso dos recursos disponíveis, que têm sido amplamente demandados. Dados do formulário de avaliação do curso, preenchido pelos participantes, indicaram que $\mathbf{8 9 , 5 \%}$ deles avaliaram como "concordo plenamente" que os conteúdos do curso contribuíram com a sua aprendizagem e com a sua prática docente (SÃO JOSÉ DO RIO PRETO, 2020c).

O Programa Rio Preto Educ Ação continua a ser d/esenvolvido, visto que o contexto de pandemia se mantém e, assim, a partir de agosto as ações de acompanhamento e apoio aos gestores(as) escolares no desenvolvimento de seu trabalho na escola foram intensificadas, mediadas pela equipe de Capacitação da SME.

\section{Considerações finais}

O estudo documental desenvolvido na abordagem qualitativa, com o objetivo de apresentar e discutir brevemente aspectos da implementação de um Programa Educacional municipal criado em contexto pandêmico, deixou evidente algumas possibilidades de trabalho e também limites e desafios. Os dados indicaram estratégias e ferramentas que possibilitaram a continuidade de vínculo entre escolas, professores(as), crianças e famílias, bem como a continuidade de trabalho de docentes e gestores(as).

Como limites, infere-se a necessidade de avaliação constante de ações e propostas vinculadas ao Programa, tendo em vista que ele continua a ser desenvolvido e o contexto pandêmico se mantém. Entende-se que esta avaliação deverá ser feita levando em conta variados aspectos, bem como deverá contar com a participação de todos os envolvidos nesse processo, objetivando que as atividades pedagógicas a distância sejam intencionais, efetivas e não excludentes, garantindo os direitos educacionais de bebês e crianças e indo ao encontro de uma determinada concepção de criança, de infância e de educação infantil, pautada nas leis e documentos norteadores, mesmo em um cenário tão complexo, urgente e inédito.

A garantia de acesso aos materiais e propostas apresentou-se como um desafio, pois a comunidade escolar mais pobre permanece à margem do acesso à informação e às tecnologias. Outro desafio foi a participação efetiva dos(as) professores(as), desde a elaboração do Programa, à adesão e seu desenvolvimento. Dentre esses desafios há também a necessidade constante, na rede pública de ensino, de firmar a identidade da educação infantil como espaço singular, formal e coletivo de cuidar e de educar bebês e crianças pequenas, não incorrendo no erro de práticas docentes voltadas a uma formação escolarizante e propedêutica. 


\section{Referências}

BOGDAN, R.; BIKLEN, S. Investigação qualitativa em educação. Porto: Porto Editora, 1994.

BRASIL. Base Nacional Comum Curricular. Educação Infantil. Brasília. MEC. SEB. 2018.

BRASIL. Ministério da Educação. Diretrizes curriculares nacionais para a educação infantil. Brasília, DF: MEC, 2009.

BRASIL. Ministério da Educação e Cultura. Lei n 9394, de 20 de dezembro de 1996. Dispõe sobre as Diretrizes e Bases da Educação Nacional. Brasília, DF: MEC, 1996.

CORREIA, B. CÁSSIO, F. Sem proteger crianças no isolamento, governos brincam de fazde-conta. Disponível em: <https://ponte.org/artigo-sem-proteger-criancas-no-isolamento-governosbrincam-de-faz-de-conta/>. Acesso em: 20 nov. 2020.

ESTRELA, B. LIMA, L. CNE aprova diretrizes para escolas durante a pandemia. Disponível em: <http://portal.mec.gov.br/index.php?option=com_content\&view=article\&id=8905 I >. Acesso em: 20 nov. 2020.

SÃO JOSÉ DO RIO PRETO. Secretaria Municipal de Educação. Brincadeiras e interações: um convite às famílias e crianças para brincarem juntas. São José do Rio Preto, 2020a. In: . Secretaria Municipal de Educação. Projeto educativo e plano de trabalho. São José do Rio Preto, 2019.

SÃO JOSÉ DO RIO PRETO. Secretaria Municipal de Educação. Relatórios sobre as ações do Programa Educ Ação: educação infantil. São José do Rio Preto, 2020c.

SÃO JOSÉ DO RIO PRETO. Secretaria Municipal de Educação. Resolução n 04/2020. Regulamenta o Programa Rio Preto Educ Ação. São José do Rio Preto, 2020 b.

SÃO PAULO. Secretaria Estadual de Educação. Secretaria Municipal de Educação. UNDIME-SP. Orientações às famílias dos estudantes das redes estadual e municipal de São Paulo. São Paulo: 2020.

SÃO PAULO. União Nacional dos Dirigentes Municipais de Educação - UNDIME. Currículo Paulista. São Paulo: SEESP, 2019.

SOUSA, A. L. H. Da tela pra cá é diferente: Trabalho docente e ensino a distância nas escolas privadas. Disponível em: <https://diplomatique.org.br/trabalho-docente-e-ensino-a-distancia-nasescolas privadas/?fbclid=IwAR0SxelFgr7KIOdNOJvleA0TO7jmlJ8JAoiSItSB9txYax|4zY7fjN63pU>. Acesso em: 20 nov. 2020.

Recebido em: 28 de maio de 2020.

Versão corrigida recebida em: 20 de outubro de 2020.

Aceito em: 10 de dezembro de 2020.

Publicado online em: 01 de abril de 202 I.

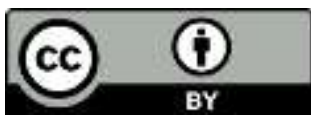

Olhar de professor, Ponta Grossa, v. 24, p. I-8, e-I5586.026, 2021.

Disponível em <https://revistas2.uepg.br/index.php/olhardeprofessor> 